Available online at GSC Online Press Directory

GSC Biological and Pharmaceutical Sciences

e-ISSN: 2581-3250, CODEN (USA): GBPSC2

Journal homepage: https://www.gsconlinepress.com/journals/gscbps

(RESEARCH ARTICLE)

\title{
Study of pharmaceutical demography in Senegal
}

\author{
Ndao Youssou * \\ Laboratory of Pharmacy Galenic and Legislation, Faculty of Medicine, Pharmacy and Odontology (F.M.P.O.), University \\ Cheikh Anta Diop of Dakar P.O Box 5005, Dakar-Fann, Senegal.
}

Publication history: Received on 03 June 2019; revised on 01 August 2019; accepted on 03 August 2019

Article DOI: https://doi.org/10.30574/gscbps.2019.8.2.0100

\begin{abstract}
From 1973 up to now, the number of pharmacies and pharmacists in practice has considerably increased, particularly in Dakar. However, the current situation is characterized by a grow in pharmacists number. The objective of our work was to study pharmaceutical demography, to address future challenges facing the profession. This is a retrospective study from 2009 to 2015 on Senegal's pharmaceutical demography, conducted at the college of pharmacy headquarters, located at Mermoz-Sacré-Cœur in Dakar region. In Senegal, the number of pharmacies and pharmacists have seen a growing trend, rising from 852 in 2009 to 1080 in 2015 . Of the 14 regions, Dakar, Thies and Diourbel have shown an upward trend. The number of staff in Section B, except biologists which is constant, has changed slightly for pharmacists and pharmacists assistant. As for Section A, it has increased slightly with a total of 177 enrolled, including 60 academics. Pharmaceutical demographics, including the number of pharmacists, have grown significantly in Senegal, between 2009 and 2015.
\end{abstract}

Keywords: Staff; Pharmacists; Pharmacy; Demography; Section; Senegal

\section{Introduction}

Pharmacy is a liberal and social profession whose purpose is to provide intellectual and technical services for client's interest or public, with respect for professional ethics. [1]

In France, 1941 Act requires a license to any pharmacy regularly exploited [2]. It's the same in Senegal, where a license is essential to open a new pharmacy [3], except exemption provided by Decree 55-1122 of August 16 th, 1955.

When the College of Pharmacists was established in 1973, there were about thirty pharmacies poorly distributed in the country, with nearly 80\% in Dakar; some pharmacists practicing in public service, particularly at the University of Dakar and in hospitals [4].

During this period, the criteria for distribution of pharmacies remained constant at one pharmacy for 15,000 inhabitants from 1987 to 1995 in Dakar region. But these criteria evolved between 1995 and 2007, to move from 10,000 to 5,000 inhabitants. Thus, the number of pharmacies has increased. At the end of 2011, Senegal had about 700 pharmacies of which (78\%) had settled in Dakar, and the rest (22\%) distributed among other localities [5]

The current situation is characterized by an increase in the number of practicing pharmacists, administrative regions which grows from 11 to 14 and new public health challenges; in an environment marked by strong financial constraints for state and people. [6] As a result, the number of young unemployed pharmacists is steadily increasing.

\footnotetext{
${ }^{*}$ Corresponding author

E-mail address: ndao.youssou@gmail.com
}

Copyright (C) 2019 Author(s) retain the copyright of this article. This article is published under the terms of the Creative Commons Attribution Liscense 4.0 
Therefore, the current number of pharmacists, as sectors of professional activities, licensed pharmacies and their distribution over the national territory, are not under control.

The objective of our work was to study the pharmaceutical demographics from 2009 to 2015, to better address future challenges facing our sector.

\section{Material and methods}

This is a retrospective study from 2009 to 2015 on Senegal's pharmaceutical demography, conducted at the College of Pharmacists headquarters, located at Mermoz-Sacré-Cœur in Dakar. Data collection was done using archived pharmacist registration forms. In addition, data obtained were analyzed by comparison with other similar data from the literature.

\section{Results and discussion}

Despite a low data completeness at the level of the College of pharmacists, coupled with a poor filling of registration forms, we obtained the following results

\subsection{Changes in pharmacies demography from 2009 to 2015}

In Senegal, pharmacies have shown a growing trend from 852 pharmacies in 2009 to 1080 pharmacies in 2015.

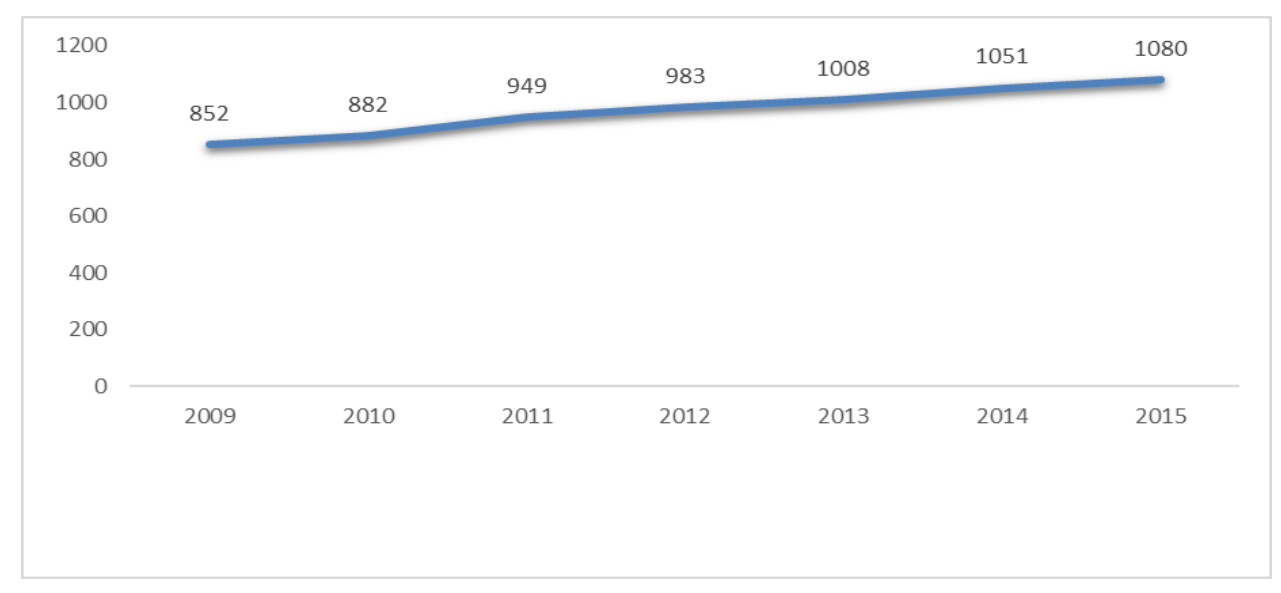

Figure 1 Changes in pharmacy demography from 2009-2015

Our results differ from those of France, where the number of pharmacies has decreased over a period of six years. It went from 22462 pharmacies in 2008 to 21772 in 2014 [7]

In Senegal, despite aforementioned increase in pharmacies number, pharmaceutical sector is facing difficulties. According to statistics from private wholesalers, $40 \%$ of pharmacies are struggling, and 20 to 25 pharmacies closed each year. [8]

However, apart from this situation, 228 licenses were issued in 6 years for the operation of pharmacies; a positive increase in the number of $21.11 \%$. This growing trend over years shows that pharmacy sector remains one of the most attractive areas of our profession.

Analysis of data collected over the period studied, shows an uneven distribution of pharmacies in regions (Fig.2).

Among the 14 regions of Senegal, 3 are evolving. These are Dakar, Thiès and Diourbel regions. Dakar region went from 494 pharmacies in 2009 to 570 in 2015; an increase of 76 pharmacies in 6 years. Regarding Thies region, it increased from 104 in 2009 to 145 pharmacies in 2015, a development of 41 pharmacies in 6 years. Diourbel shows a lower evolution in the same period, from 34 to 60 pharmacies. This situation is explained by the fact that the establishment of pharmacies is proportional to the number of inhabitants, as it results in accordance to the last official census of the population [10]. Dakar is more populated than Thies and Diourbel. There is also the fact that economic activities concentrated in these areas argue in their favor respectively. 


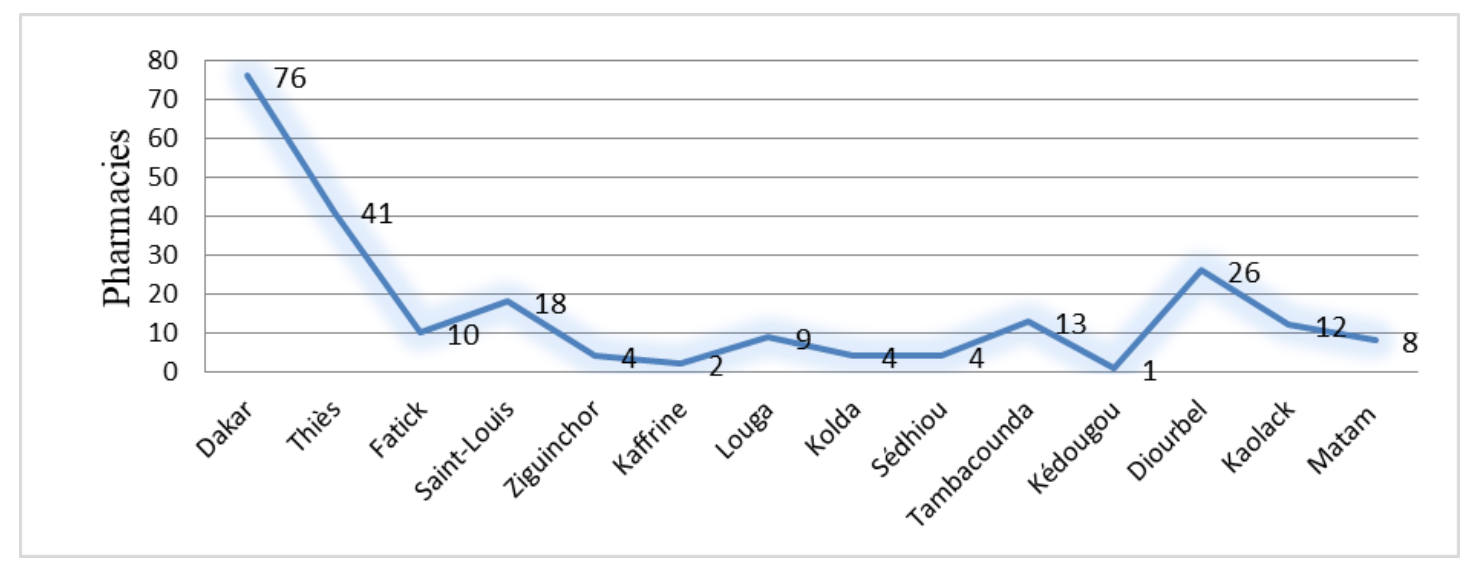

Figure 2 Change in pharmacy demography according to regions

Regarding regions of northern axis (Saint-Louis, Louga and Matam), progression is the same, except a slight change for Saint Louis region, which could be explained by its proximity to Mauritania. It's not the case for Louga and Matam which have the same number of pharmacies during the study period.

About regions of southern axis, Ziguinchor and Kolda have the same progression. New regions like Sedhiou, Kaffrine and Kedougou are neither attractive nor economically viable at the moment. Furthermore, this innovation could justify the lack of pharmacies in these localities.

If we refers to pharmacies standards establishment (1 per 5,000 inhabitants) [10], only Dakar region with 3,137. 196 inhabitants complies (density $=5602$ ). As for new areas (Kaffrine density $=70,874$; Sédhiou density $=90598$; Kedougou density $=50452$ ), they are very remote standards. However, in regions like Thies, St. Louis and Ziguinchor standards are acceptable.

Disparity in coverage of pharmacy needs could be related to several factors, such as the preference of pharmacists to settle in regional capitals for the benefit of economic activity areas. It's a situation different from that of France where rural areas are not deserted, and where harmonious distribution of pharmacies remains a reality throughout the territory [7].

\subsection{Changes in demographic staff}

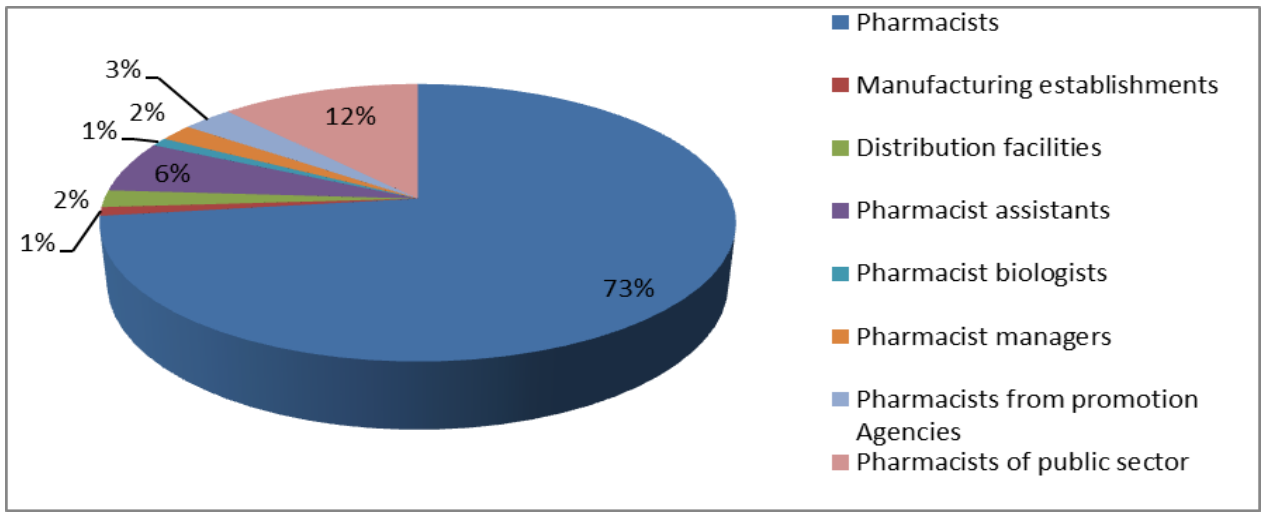

Figure 3 Categories of staff by sector of activity

\subsubsection{Changes in section $B$ staff}

In Senegal, the number of pharmacies continues to grow, reaching a total of one thousand eighty (1080) in 2015. However, the number of registered pharmacists is estimated at one thousand and forty eight (1048).

With regard to the number of ninety (90) or six percent (90\%) assisting pharmacists, the number of pharmacists did not change significantly, compared to the number of thousand eighty-eight (1048) seventy-three percent (73\%). This can be explained by the fact that some assistant pharmacists do not register to the College of pharmacists; there is the 
fact that some incumbents have difficulty recruiting assistant pharmacists. In addition, the order provision on pharmacy assistantship is not yet applied [9].

Our results show a significant imbalance between staff and assistant pharmacist's number. This is a different situation in France, where the proportion of assistant pharmacists registered at the College of pharmacists (36.7\%) is almost identical to that of pharmacists (36.8\%). [7]

Regarding biologists, their number is constant and limited to 18, including 15 managers and biologists, 3 assistants enrolled in the College of Pharmacists. This could be explained by several factors including inadequate recruitment of assistant biologists, installation of biology laboratories in most clinics, difficulties to obtain funding for opening a medical biology laboratory.

Unlike French pharmacists biologists which represent ten per cent (10.1\%) of pharmacists enrolled in the College of pharmacists [7], biologists in Senegal are not numerous, one per cent (1\%) registered.

About manufacturing facilities, Senegal's pharmaceutical industry is made up of four local drug manufacturing units: Aventis-pharma, Pfizer West Africa, Canonne S.A laboratory (Valdafrique), Pasteur Institute and recently West Africa Pharma subsidiary of Sotheme. According to information collected, the number of head pharmacists has not changed, and remained at fifteen (15) registered pharmacists, including eight (8) head pharmacists and seven (7) assistant pharmacists. Results confirm the fact that production sector in the pharmaceutical field is not very developed in Senegal, where only ten to fifteen (10 to 15\%) of the country's needs in medicines are met by local pharmaceutical manufacturers [11].

With respect to wholesaling companies, the lawful commercialization of drugs is provided by two channels: a private sector with eighty per cent (85\%) of the licit drug market value and a public sector represented by national supply pharmacy. It is a sector which also has significant appeal with a growing number of distribution facilities Wholesale, which is increased from four to six private wholesalers (Laborex Cophase, Sodipharm, Sogen, ECOPHARM and Duopharm). It was followed by a rise in the number of head pharmacists twenty eight (28). However, despite progress observed, this workforce represents only two per cent of regularly registered pharmacists. Similar results were observed in France, where they represent one per cent of pharmacists. [7].

\subsubsection{Changes in section $A$ staff}

According to the results collected, we find that number of pharmacists enrolled in private sector, is at least greater than in public sector. Indeed, Section A comprises thirteen of pharmacists, against eighty seven per cent of pharmacists in private sector. Despite this situation, there was a slight increase in section A enrollment with a total of one hundred and seventy seven, were sixty of which are university-level. This situation could be explained by the fact that public sector is less attractive on one hand, and on the other hand by low recruitment of pharmacists in both public service and higher education.

\section{Conclusion}

The number of pharmacist's staff in section B and the number of pharmacies, grew from 2009 to 2015. However, there are regional disparities, with a significant increase in regions of Dakar, Thies and Diourbel, and a low growth in other regions. The number of biologists and head pharmacists has not moved, except a slight change in the number of head pharmacists for wholesaling establishments. As for section A staff, it has grown slightly.

\section{Compliance with ethical standards}

\section{Acknowledgments}

I am indebted to Miss Vanessa doctor of pharmacy, and College of pharmacy staff for their help and support during this research work.

\section{Disclosure of conflict of interest}

We have no conflicts of interest to disclose. 


\section{References}

[1] Liberal professions: a legal definition. From the newspaper of French College of Pharmacists: No. 16, JulyAugust 2012.13.

[2] Law of 11 September 1941 on pharmacy practice. Title IV, Terms of practice of retail pharmacy. Chapter I: Pharmacies. Art 21, p.4020. Official Journal N ${ }^{\circ} 4018$ of September $20^{\text {th }}, 1941$

[3] Law 54-418 of April 15, 1954 on Book V pharmacy - Title II - Specific provisions to various modes of pharmacy practice - Chapter I: Conditions of pharmacy practice - Section 1: Pharmacies. Article L.570

[4] El Hadji Malick DIOP. College of Pharmacists and new public health challenges. Memory for Master's degree in Pharmaceutical Inspectorate presented on Monday January 5th, 2015 at Dakar. Number 10.

[5] National Pharmaceutical Policy. Department of Pharmacy and Laboratories Ministry of Health and Medical Prevention.

[6] World Health Organization. Private commercial pharmaceutical sector in Senegal. Development dynamics and effects on access to essential drugs. Research Series No. 23

[7] France College of Pharmacists - Demographic Elements. Pharmacists - Panorama January 1, 2015.

[8] Introductory Report to the Inter-Ministerial Council on Pharmacy Sector in Senegal. Year 2013.

[9] Article 1 of Decree No. 9089 of December 14th, 1988 determining annual turnover of assistant pharmacist recruitment.

[10] Decree No. 2007-1457 of December 3, 2007 setting criteria for the establishment, of transfer and distribution of pharmacies.

[11] Ndao Y and Diarra M. (2018). Development of Pharmaceutical Industry in Senegal. Research article, 6(1), 25.

\section{How to cite this article}

Ndao Y. (2019). Study of pharmaceutical demography in Senegal. GSC Biological and Pharmaceutical Sciences, 8(2), 01-05. 